\title{
School Leadership and Capacity Building in Kazakhstan
}

\author{
Natallia Yakavets ${ }^{* 1}$, David Frost ${ }^{1}$, Aidar Khoroshash ${ }^{2}$ \\ ${ }^{1}$ Faculty of Education, University of Cambridge \\ ${ }^{2}$ Graduate School of Education, Nazarbayev University
}

\begin{abstract}
The article examines the scope for initiative and independent action that lies with school principals in Kazakhstan, with a particular focus on capacity building approaches. A framework drawn from Hargreaves (2001) and Dimmock (2012) guided our inquiry. The study is situated within a large collaborative project between three institutions: the University of Cambridge Faculty of Education, Nazarbayev University Graduate School of Education and Nazarbayev Intellectual Schools. A mixed method research design was used to collect data in 20 schools and 11 other educational organisations in six different geographical locations in Kazakhstan. The findings suggest that capacity building strategies are necessary if innovations are to be implemented across all schools. The article outlines the challenges involved in making school reform effective and draws on the 'capital framework'. The conclusion considers the implications for practitioners and policy-makers, and outlines an agenda for further research.
\end{abstract}

\section{Introduction}

This article describes findings from a large collaborative research project between three institutions: the University of Cambridge Faculty of Education, Nazarbayev University Graduate School of Education and Nazarbayev Intellectual Schools (NIS). This is a 5-year research project that was initiated in 2012. From a research perspective the focus of each year studies can be seen as to build cumulatively upon each other: in 2012 we conducted 'a scoping study' of policy-makers perspectives of the reform process - the 'policy formation'; in 2013 we explored how reforms were perceived on the ground in schools and local

\footnotetext{
* Corresponding author. Email: ny250@cam.ac.uk
} 
educational authorities; and in 2014 we were looking at the process of implementation of educational initiatives from the school and other key stakeholders perspectives. The overall focus and themes of each year research are negotiated on a year-by-year basis between the partner institutions. In 2014 a team of twenty researchers from three institutions was looking at six themes: the role of school leaders and teachers in educational reform; teachers' identity; the 'translation' of new curriculum and assessment from Nazarbayev Intellectual School experience to mainstream schools; school assessment; school autonomy; and the transition from school to university. In this article we explore how school leaders in Kazakhstan respond to the challenges of education reform and, more importantly, how conditions in the schools enable the process of reform to actually transform practice and the role of leadership in creating those conditions.

Our research on educational leadership in schools in Kazakhstan is shaped by the assumption that not only should it investigate matters relevant to the process of reform but that it should also contribute to this process. Recently published accounts of the early stages of our research (Bridges et al., 2014) set out in some detail how the recent history of Kazakhstan has been characterised by repeated waves of educational reform. The impetus for the research arises from the current push for reform which involves a desire to look to other countries, including the UK and USA, for expertise and knowledge (Bridges et al., 2014). Not surprisingly, perhaps, most research in the field of educational leadership has been informed by the experience of educational systems in the UK and other similar societies. However, from the point of view of our research in Kazakhstan this is problematic, and we are very aware of the dangers of allowing our analysis to be distorted by assumptions derived from what is known about educational change in these cultural contexts. One safeguard is that, as researchers, we work collaboratively in a team which brings together knowledge and experience from Anglophone countries, Kazakhstan and other parts of Central Asia.

Education reform requires political will and accompanying strategic plans, which we can safely say exist in abundance in contemporary Kazakhstan. Initiatives that emanate from the centre seem to have a clear rationale and explicit plans for dissemination. Indeed, our research hitherto indicates that key messages are reaching the schools in the regions far from the capital city and there is good evidence to show that practice is beginning to change in response to these initiatives (Turner et al., 2014). Nevertheless, it is the case that the education system in Kazakhstan is only at the beginning of its reform journey, with a need 
not only to embed current initiatives but also to build on them to meet future challenges. School leadership has a pivotal role to play in this. The relationship between the reform process and school leadership for capacity building, however, has yet to be adequately explored.

The article is divided into several parts. In the first part we outline the research context from which the empirical data are drawn. Next we discuss some conceptual building blocks which inform our understanding of leadership and capacity building. The third part offers a description of the design of the study and an analysis of the data collected in the inquiry. Then we discuss the results of the study and the relationship between a school's capacity and the challenge of educational reform in a non-Western context. The final part offers some thoughts on the implications of the analysis for leadership support and policy-making, how article contributes to the existing literature, and what further research is required.

\section{Research context}

In 2013-2014 the school sector in Kazakhstan had 7,561 full-time schools (including comprehensive schools, gymnasia and lyceums), enrolling about 2.5 million students and employing around 310,000 teachers ${ }^{\mathrm{i}}$. There is a considerable number of schools called 'ungraded' (Rus.'malokomplektnaya shkola') located mainly in rural areas and often characterised by a low quality of education (MoES, 2010). Another important characteristic of the school system in Kazakhstan is the presence of government-funded schools for gifted and talented pupils. These schools operate under the umbrella of three major networks: the Republican Research and Practical Centre, otherwise known as "Daryn" (giftedness in Kazakh), the Kazakh-Turkish Lyceum, and the Autonomous Educational Organisation Nazarbayev Intellectual Schools (AEO NIS) (see Yakavets 2014). These schools receive an additional funding scheme and provide an in-depth curriculum in specialized subjects. There is a competitive selection process for them, which is independently determined by the managing organisation of each network. High performing schools are often selected by the Ministry of Education as a pilot (or experimental) for educational initiatives such as: 12-year schooling, tri-lingual policy; e-learning; and translation of the experience of implementing new curricular initiatives and criteria-based assessment. 
Despite years of reform and attempts at decentralization, the education system remains highly centralised and bureaucratic. As the 2013 World Bank SABER Report describes: 'While education policy is the responsibility of the Ministry of Education and Science, the municipal level's (Kaz. Akimat) education departments are responsible for delivery' (The World Bank 2013, p.2). The report judges Kazakhstan to fall into its 'emerging' category with respect to 'autonomy in budget planning and approval' (p.6). Schools are regulated by various normative documents and are required to report to monitoring agencies. Furthermore, the internal structural organisation of the school system has not changed greatly from the Soviet era. All national-scale educational experiments are also centrally initiated.

The Ministry of Education and Science (MoES) sets educational goals and standards (Rus. GOSO), and controls the national curriculum in a way that leaves only limited scope for principals' or teachers' involvement. The standards shape the mandatory part but the elective part of the curriculum provides some room for schools' self-determination: they can select subjects for the curriculum depending on their own goals, as well as according to teachers' and students' abilities and interests. Furthermore, schools are independent in 'a choice of forms, means and methods of teaching defined in their charters' (Decree No.499, 2013, p.228).

The head of a public school is determined and appointed on a competitive basis based on the decision made by the Akimat regional department of education, with consultation provided by the MoES. Traditionally a principal's contract would be continuously extended but, since 2012, there is a new regulation that, after each five-year period, there must be competition for the school principal's position (MoES 2012). School principals have responsibility to hire and dismiss teachers, assess teachers' performance, respond to local authority and ministerial decrees and orders, and maintain student discipline. However, school principals do not have a right to refuse the decision of the department of education in respect of hiring new teachers who have just graduated from pedagogical universities. The newly qualified teacher's placement at school is compulsory across the country.

The legislation (e.g. the Standard Regulations for Operation of Educational Organisations, 2013) states that the school principal is accountable to local education authorities for:

- Compliance with state educational standards; 
- The welfare of students and employees of academic institutions with the educational process;

- Financial and economic activities, including the misuse of material and financial resources;

- To prevent violation of the rights and freedoms of students and employees of educational institutions (Decree No.499, 2013, pp.2-33).

As these requirements show, a considerable part of the principal's role is to do with ensuring compliance to state norms rather than focusing on strategic school leadership. The central and regional/local educational authorities assess principals' performance every three years. There are clear criteria for passing an attestation process and, as our research (in 2013) has indicated, the main criteria for evaluating principals' performance are students' results and the number of students and teachers who win regional, national and international competitions - often called 'Olympiads'.

The current educational agenda in Kazakhstan, elaborated in the State Programme of Education Development (SPED), is likely to have a significant impact on the practice of school leaders across the country. One of the SPED's objectives is: 'the improvement of education management including implementation of corporate governance principles' (Objective 4:3). Furthermore, Frost et al. (2014) and the latest international and national reports (e.g. OECD, 2014; World Bank SABER, 2013) highlight the importance of enhancing the quality of leadership in Kazakhstani schools and extending the degree of autonomy for principals.

Opportunities are being developed for teachers and principals in contemporary Kazakhstan to learn new skills and develop professionally (see Bridges 2014, Turner et al., 2014). In general, the dissemination of leadership ideas in the country occurs through a set of leadership courses as part of school administrator and teacher in-service training provided by the National In-Service Professional Development Institute, 'Orleu', and by the Centre of Excellence $^{\mathrm{ii}}$ programme that operates as a division of the Autonomous Education Organisation (AEO) Nazarbayev Intellectual Schools (NIS). As Turner et al. state 'the normative re-educative models of training principle requires training to involve critically evaluating existing practice as well as examining the principles underpinning pedagogic approaches, and making changes to practice in the light of these considerations' (2014, p.88). 


\section{Conceptualising leadership and capacity for reform}

Research in America, Canada, Britain and Australia tells us unequivocally that successful school leadership is a key factor in school effectiveness (e.g. Hallinger and Heck, 1996; Leithwood et al., 2004), but what is needed is insight into how school leadership can enable transformation rather than merely maintaining the status quo. A few years ago it was argued that the most robust studies of leadership effects (Hallinger and Heck, 1996, 1998) did not distinguish between different types of leadership practice (Leithwood and Jantzi, 2006). Since then, studies have been able to show an association between learning outcomes and particular forms of leadership practice, including for example the enabling of distributed leadership (e.g. Hallinger and Heck, 2010). However, only recently has empirical research begun to develop explicit links between patterns of successful leadership practice and different types of school context (e.g., Hallinger and Heck, 2011; Day et al., 2010; Hallinger, 2003). Hallinger and Heck (2011), in their discussion of 'context' refer to environmental and organisational conditions that moderate a school's capacity for improving student learning.

Sleegers and Leithwood (2010) identified two views that have dominated theory and research about school improvement and educational change. The 'inside view' focuses on the capacity of schools to transform themselves into supportive environments for teacher learning and change; while the 'outside view' concerns the implementation of externally developed reform designs within schools.

The inside view is represented by a wide range of studies about organisational learning, learning organisation, and professional communities (Mulford and Silins, 2009; Hopkins, 2001; Leithwood, Aitken and Jantzi, 2001; Leithwood, Jantzi, and Steinbach, 1999; Leithwood and Louis, 1998; Mitchell and Sackney, 2000; Senge, 1990). In these studies, organisational conditions, including leadership, are considered as the main levers of a school's capacity to change and as a prerequisite for linking principals' and teachers' professional development to school development (Thoonen et al., 2012, p.443). The outside view, concerned with the implementation of innovations or new practices developed by reformers and policy-makers, is represented by studies into the effects of comprehensive school reform models and the transfer of these models to multiple settings ('scaling up') (Borman et al., 2005; Desimone, 2002; Sterbinsky et al., 2006). Findings from these studies indicate that some comprehensive school reforms have modest effects on student 
achievement, but most have little effect (Thoonen et al., 2012). Moreover, the results also seem to suggest that schools which already have a high school-wide capacity for improvement and are able to transform their organisation into a rich learning environment for teachers can integrate externally developed reforms into their current practice more easily than schools with a low improvement capacity (Thoonen et al., 2012, p.444).

Our own previous research on school leadership in Kazakhstan clearly showed that school principals (Rus. directors) tend to put a great deal of energy and time into communicating reform objectives to their staff (Frost et al., 2014). However, the assumption that a combination of information and exhortation will result in effective implementation is highly questionable. Part of the problem is concerned with the issue of fidelity. McLaughlin (2008) cites Spillane, Reiser and Reimer (2002) to show how innovations are likely to be reframed and refocused because regional and institutional leaders' understanding and interpretations of initiatives depend on their previous experience. She points out that respondents will often say that 'we're already doing it' when this really reflects a lack of understanding about what 'it' is. This reminds us of the limitations of the concept of 'implementation'. However, a more serious aspect of the problem concerns capacity building because our earlier research has suggested that school directors in Kazakhstan have almost no scope for organisational development (Frost et al., 2014).

In a milestone empirical study by John Gray and colleagues, the idea of capacity building was brought into sharp focus when it was found that short-term tactical approaches to school improvement were the least effective in achieving continuous improvement. Strategic approaches were more effective, but the schools that were demonstrably more able to sustain improvement were those which engaged in capacity building (Gray et al., 1999). The question for us here is how such capacity can be built in schools in Kazakhstan.

\section{Capacity building}

Policy analyses regard capacity building as one of a number of instruments - like mandates, inducements and system-building mechanisms - that policy-makers can use to translate policy goals into actions (McDonnell and Elmore, 1987). Mitchell and Sackney (2000) view capacity building as needing to take place within and between three interconnected areas, or spheres: the personal, interpersonal and organisational. The idea of schools having a certain 
'capacity', or 'capacities', for dealing with change, for improvement or for leadership, has been widely discussed in the Western literature (Newmann et al. 2000; Hopkins and Reynolds, 2001; Hopkins and Jackson, 2001; Stoll et al., 2003; Hargreaves, 2001; Fullan, 2005, 2010; Hargreaves and Fink, 2006; Fink, 2011).

It is tempting to think that the capacity for continuous improvement can be built by providing training programmes to ensure that teachers are updated (i.e. the personal capacity), but this fails to address the other two dimensions mentioned above. In order to build interpersonal and organisational capacity, school leaders need to develop the organisation of their schools in terms of roles of responsibility, structures of accountability, patterns of collaboration, evaluation procedures, and the activities that support professional development. From our previous research it is clear that this is a particular challenge in the Kazakhstani system because of the lack of a tradition of school autonomy.

An alternative or at least complementary way to conceptualise capacity is the idea of capital. The social science literature presents a range of types of capital: 'physical', 'financial', 'human', 'cultural', 'social', 'economic', 'intellectual', 'political', 'ethnic' and 'symbolic' are often described (Yakavets, 2011, p.25), and more recently 'professional capital' (Hargreaves, A. and Fullan 2012) has been introduced. In 2001, David Hargreaves offered a view of school effectiveness as pivoting on the extent and quality of a school's capital, which he argued could be analysed in three dimensions: intellectual, social and organisational.

Intellectual capital consists of the knowledge, skills, values and expertise of individuals within the school community. It is relatively straightforward to audit intellectual capital - that is to identify the knowledge, skills and expertise of members of the organisation - but the challenge for capacity building is to enable individuals to turn this into organisational capital to enable individuals to put this to effective organisational use. This requires that attention be paid to social capital - trust, respect, collaboration and networks. An audit of the social capital an organisation possesses would identify not only the quality and extent of the internal networking arrangements - who talks to whom, how, when where and about what? - but also the level of trust that enables people to feel able to engage with each other and share their knowledge and expertise (Bryk and Schneider, 2002). 
Hargreaves (2001) claims that 'organisational capital' is particularly critical to the efficacy of the school as an organisation. Dimmock (2012) describes 'organisational capital' as the knowledge and skill about how to change the school by making better use of its intellectual and social capital to produce high-leverage strategies of teaching and learning. Organisational capital falls within the purview of leadership, as leaders are tasked to devise new forms of organisational capital to enable transformation of teaching and learning (Dimmock, 2012, p. 19), as indicated in the Figure 1 below.

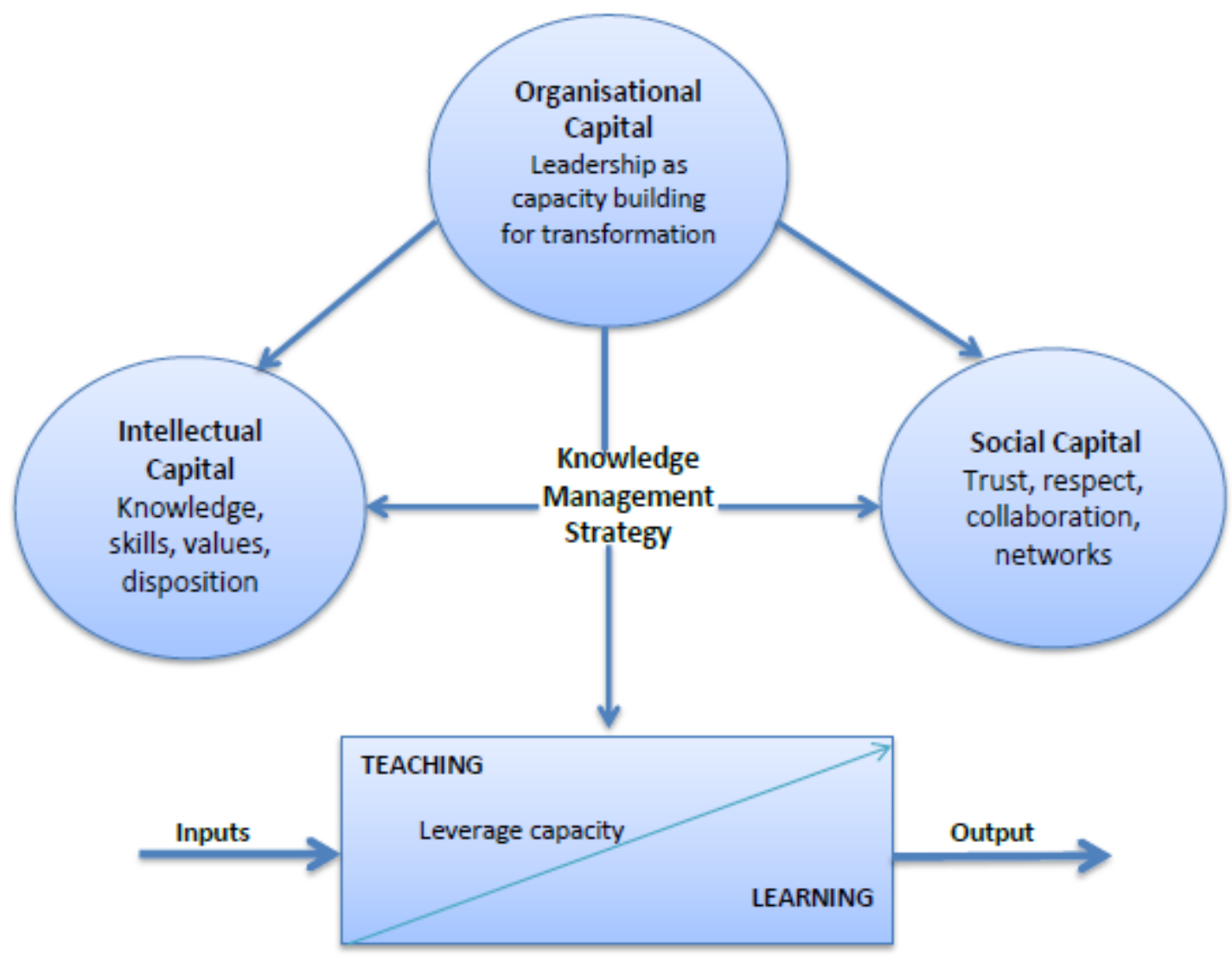

Figure 1. Conceptualisation of leadership as capacity building - utilising intellectual, social and organisational capital. Source: Adapted from Dimmock (2012, p.19).

Furthermore, as Dimmock (2012, p.20) argues, 'the central business of leadership is to develop the various capacities and capitals forming the assets of the school'.

The research discussed above makes clear that capacity building is a crucial factor in school effectiveness; it is also a key dimension of school improvement, but for our purposes in looking at school leadership in Kazakhstan, we need to ask a more specific question which is about the relationship between a school's capacity and the challenge of educational reform. We do not assume that what is known about the links between capacity and effectiveness or even the link between capacity and improvement can be straightforwardly applied to large 
scale and fundamental reform of an education system which in many respects is very different from those in the West. For the purpose of this paper, our definition of capacity building concurs with that of Bain et al. (2011), who define it as a 'set of coherent, deliberate strategies enacted at a whole school level to positively influence the knowledge, skills, and priorities of individuals and the school as a collective as together they seek to implement change' (Bain et al., 2011, p. 701).

\section{Research methodology}

The overall 2014 research project was designed as a mixed-methods study drawing on semistructured interviews, focus groups, and a survey, as well as the analysis of documents published by the Ministry of Education and Science, Nazarbayev Intellectual Schools, and regional departments of education. For the leadership strand of the work, the primary source of data is interviews and this is what will be reported on here. To make the research process manageable (not least to ensure we had sufficient appropriate language competence in Russian and Kazakh), and to meet various interests of a multi-disciplinary researcher team, six sub-teams were created dealing with separate strands of the research. Three or four researchers were attached to each team with a lead-researcher responsible for each strand. A few people were involved in two or three teams at the same time. The research expertise, experience and specific research interests of team members were major elements of the divisions. Each thematic team identified key research questions which guided the data collection. For this paper, the primary source of data is interviews and focus groups which explored the leadership practices in twenty schools. The specific research question was:

- In the context of intensive national reforms, how do schools in Kazakhstan create the conditions for capacity building in their day-to-day operations?

Data were gathered during two field visits: in February/March 2014 to four locations and in May 2014 to two new locations in Kazakhstan. The sample included schools for gifted and talented children (NIS, Daryn); mainstream schools (comprehensive and gymnasium); and small multi-graded schools operating in different social settings (urban/rural; high/low SES) in six geographical locations within Kazakhstan. Some schools had over a hundred

years of history, while others were less than one year old. The selection of schools to be 
involved in the research was made with a view of getting an understanding of implementation of educational initiatives in different types of schools across the country. Participants in this study were: school principals, deputies, and teachers (local and international), parents, representatives of Boards of Trustees in some schools, 10th and 11th grade students in schools, senior managers of Nazarbayev Intellectual Schools (NIS), officials in the local educational departments, rectors and deans at seven different HE institutions, and the first year students in those institutions. There were 19 principals involved in the study including 13 female and 6 male. Involvement in the study was on a voluntary basis and all participants were informed of the purpose of the research and were provided with informed consent forms in Kazakh and/or in Russian.

Interviews and focus groups were conducted by between one and three researchers in the language of choice of the interviewee: in Kazakh and/or in Russian. A few interviews were conducted in English using a semi-structured interview protocol. All interviews were digitally recorded after permission was obtained from participants. It is important to note that interviews with principals focused primarily on leadership and autonomy, while interviews with teachers were more concerned with issues of teacher identity and professional development.

From the 153 interviews conducted during two field trips, a large majority were in Kazakh and Russian and therefore required translation and transcribing to be accessible for analysis by the whole research team. Since this would have been extremely time- and resource-consuming to do this with all 153 interviews, when interviews were conducted notes were made by members of the research team about the usefulness (with the respect to each of the six themes mentioned above), and richness of the data collected in a particular interview. All interviews varied considerably in this respect. Each team was asked to identify up to 15 interviews they judged to be rich and useful in terms of themes covered - or more specifically to identify 'high' and 'medium' priority interviews to be translated and transcribed in English. On this basis 65 interviews were translated and transcribed. Then, interview transcripts were coded using NVivo 10 programme for the six themes. A master NVivo file was created and shared between members of the research team. Categories emerged from the data rather than being imposed on them except that the themes were pre-specified. The following were the main sub-categories developed by the team of researchers working with the 'leadership' theme: 'school culture'; 'leadership styles'; 'professional development'; 
'capacity building'; and 'accountability'. Participants were coded by their job title, Roman numbers were used for locations (I-VII), and the capital letters ' $S$ ' for schools, and 'LG' for local department of education. Findings reported in this paper are based on a synthesis of results across all twenty schools which participated in the research project.

\section{Analysis of data}

Our analysis focused on issues arising from the data that could highlight the role of school principals in educational transformation and capacity building. We organised the data under seven categories representing recurrent themes that related to the research question.

\section{The challenging nature of the principal role}

Our research findings highlighted the complexity of the principal's role. The majority of school principals felt that they were not given much freedom to decide how to run their schools and to allocate the school budget. It was claimed:

...Autonomy in the real sense...we have not come to that level yet. We are just on the way to that level. This is our destination point.

(Principal, S-D-I)

Key aspects of school work are nationally defined by: the state educational standards; high stakes assessment - Unified National Testing; the system of teacher pay; 'norms' for school furniture, electricity, water supply, stationary; and so on. Furthermore, the system of finance is under tight control by the local education departments in ways which are not transparent for principals and teachers. As data reveal, due to the ethos of high accountability that permeates the school system, the principals perceive that their roles and responsibilities are cut out for them:

...the government decides everything that I plan. It's not me who decides.

(Principal, S-D-II)

There was freedom of manoeuvre in just a few areas: 
...I can choose which subject to specialise in, whether it is Kazakh, English or any other,

I can do this. I can change hours within the curriculum, I can take hours from the elective section and add this to maths... there is a limit, but there is a limit to everything.

(Principal, S-C-II)

Another school principal stated:

...we have the independence to choose the forms and methods of teaching; this is where our school has autonomy.

(Principal, S-A-V)

The major challenge for school leaders was balancing pressures of accountability and the freedom to innovate:

...Principals have to face a lot of risks nowadays because there is not a single authority that would not come check upon school. Almost every government organisation comes to us with an inspection.

(Principal, S-C-II)

While there was an understanding of the necessity for school reform set by the Ministry, the majority of participants questioned the balance between the inspection checks and the need to create a positive environment for implementing innovations in schools. A high degree of central control - 'an inspection culture' - seems to have led to an emphasis on completing paperwork rather than focusing on teaching and students' learning. The heavy administrative duties do not let the principals enjoy the opportunity to engage with teaching and work with students. With the obligations of reporting, principals are likely to feel torn between their responsibility for instructional leadership and their other more administrative responsibilities. Despite the challenges, some participants stated that 'the role of the principal is significant in guiding the teacher on to the right developmental path'.

The results highlighted a number of ways in which school principals in Kazakhstan build capacity in their schools. The importance of teacher development and teaching quality was prioritised by the majority of school leaders.

\section{Supporting young teachers}

Nearly all schools run a mentoring programme called the 'School for Young Teachers'. At the beginning of the academic year in September the school principal and/or the vice 
principal assigns a mentor (Rus. nastavnik) to each newly qualified teacher (NQT). It is common to choose a mentor among more experienced teachers who have the highest or $1^{\text {st }}$ category of teaching qualification. The role of the mentor is to support young teachers through, for example, lesson observations and the provision of feedback. As it was noted:

During 4 years you learn everything theoretical, but to work with children and books is different.

(History Teacher, S-B-I)

Another teacher commented:

After [graduation], my colleagues - i.e. experienced teachers - were our mentors. Then we had to work for 3 years... We got knowledge at the institute but the impact of mentors was also great... we were trained to work with children.

(Teacher Focus Group, S-A-II)

It seems that, for some early career teachers, this type of support is especially important to build up their professional confidence, and also help to develop a trusting and respectful working relationship. At the same time, while younger teachers needed help with pedagogy and teaching skills they in turn could be helpful to older teachers as regards the use of ICT and other technologies. So, there was some reciprocity between different generations of teacher within schools. Furthermore, our study shows that in-house professional development occurs in a number of ways which are discussed next.

\section{Sharing practice}

The practice of sharing experience and coaching by teachers who attended the Centres of Excellence $(\mathrm{CoE})$ three-month teacher professional programme was mentioned by nearly all of the participants in the schools we studied. This was seen as an opportunity to build personal and interpersonal capacity within the schools, and overall as a positive development to improve teaching and learning. The school administration was willing to provide better equipped classrooms and different multimedia tools for trained teachers with the aim of advancing sharing practice. 
Participants acknowledged that people who attended the CoE courses 'are different', namely, 'teachers became more democratic'; they were perceived as 'advisors' on new teaching methods in some schools, and some teachers called themselves 'intellectuals'.

We have 5 teachers who completed the courses. Now each teacher is preparing two teachers. They help each other a lot. These courses are useful even for those who have not passed them. Some teachers use elements of the new technologies in the lessons they conduct. In general, the whole school is changing now.

(Two Vice Principals, S-D-II)

Similarly in another school this comment was made:

\begin{abstract}
A lot of teachers from our department participated in three month courses. And we try to use these ideas at our lessons and we have noticed it's very effective... we also share experience with other teachers and organise couching. Our teachers are very creative. They used some elements of these new approaches and techniques before. Let's say they are not so new, they are just systemised... Soviet pedagogy also practiced group work etc. But new experience is very useful for us as we have significant results.
\end{abstract}

(Physics Teacher, S-A-IV)

Indeed the majority of teachers are willing to change their practice towards a student-centred pedagogy, taking more responsibility for children's learning and development. However, the question of 'Why change?' is still a challenge faced by educators across the country. To resolve this question, one school organised debates between teachers to discuss advantages and disadvantages of 'old' and 'modern' ways of teaching. As a result, teachers felt more empowered by this experience:

...our mistake in the previous system of education was the superiority of the teacher's role. In other words, we suppressed the kids' initiatives. Today's goal is to give freedom to students... Now, if I give pupils theoretical material, they are getting the geometrical interpretation simultaneously. I believe that kids must not only see and hear, but also work with their hands.

(Teachers, Focus Group, S-A-V) 
In addition to changing beliefs it is important to make sure that school leaders are willing to do so. For this purpose, some short-term introductory courses are organised for principals and vice principals with the aim of introducing them to the overall ideas of the $\mathrm{CoE}$ professional development programme:

...The course organisers told me all about the three-level program, and its main features, the kind of modules it has, what they target, and the main emphasis. But I don't think that they told us everything they were supposed to in three days.

(Vice Principal, S-B-VII)

Similar comments were expressed by many respondents who hold senior leadership posts in other schools. The limitations of the scale of the course, which does not provide training for all senior management staff in schools across the country, are seen as one of the obstacles to reform. However, the data also reveal that school leaders' own experience of professional development courses and involvement in various education programmes (e.g. a programme about distributed leadership run by Western trainers) have a significant impact on their perceptions of their own roles within their schools. This affects how they provide support and create the environment for staff involvement in innovations more widely:

Last year, our principal was not so supportive, but this year, having travelled to [cities in Kazakhstan and Western countries], her eyes have been opened to the world, and the world opened up to her. And the way she works now, she supports every initiative - 'Go ahead, go on, do it'. So, in this regard, every teacher knows that any initiative that is beneficial for the school, for the kids, for teachers, will always be supported.

(Vice Principal, S-A-V)

\section{Creating networks and in-house events}

In one urban school, a group of teachers who attended different levels of the CoE programme set up a network consisting of three sub-groups: the first group included leaders and organisers; the second included teacher-trainers responsible for coaching, and the third group included those, who attended the Level 3 courses with a focus on leading learning in classrooms. Every month one of the groups organised an event. During these events the group leaders helped teachers to draft lesson plans and explained criteria-based assessment methods. 
...we attend teachers' classes to share experience, not to assess...we also hold training sessions by topic to solve current problems.

(Teacher 3, Focus Group, S-C-VI)

There were some examples of internal networks observed in other schools but their activities were in the process of being established and were sporadic.

In all schools a range of events such as open lessons, master-classes, seminars and workshops had been organised. Such activities were seen as necessary for teachers' professional growth. In some schools participants claimed that they were working towards establishing the sharing of practice, and were even willing to serve as a 'resource centre' for other schools, seeing mutual benefits in this:

So my position, my role is to be a resource centre. I am open to do these workshops, to invite [teachers] to visit our good lessons... we are open to share pedagogical ideas and experience. And, it helps me. It's like a sword with two edges because my teachers preparing for these workshops think again and again about all these ideas.

(Principal, S-E-V)

Some of teachers we spoke to saw the value of workshops organised in other schools, along with the impact from lesson observations:

\begin{abstract}
We observed there the new methods of teaching. Especially I noticed that my method of teaching is different but we apply what we saw in their lessons too... And we understood it very deeply. During the application of that method I observed one thing... I had a student in my class. He wasn't an underachiever; however, he wasn't active, very reserved. And this boy learned how to express his ideas! I didn't even expect from him such results taking into consideration his level. That was an impact from these colleagues' lessons which we attended. We also applied them; they showed their initiative in our team work, group works.
\end{abstract}

(Teacher-1, Focus Group, S-D-V)

Teachers were clearly beginning to adopt new ideas about learning and were beginning to change and to adapt their practice to new pedagogical beliefs and new ways of teaching. However, there were some critical points expressed that only when 'all the teachers will complete these courses (i.e. CoE) together, maybe there will be some results' and importantly 
that 'the children are wondering why this teacher uses the new educational method, and this one behaves in the old fashion' (Teacher 2, Focus Group, S-B-V).

\section{Supporting teachers to take on leadership}

The major concern expressed by some participants was the fact that people: 'are used to hearing orders from above and they still want to hear the order: "Do this"'. Still some school principals encourage teachers to take initiatives:

In this way I want my staff to learn how to tackle problems, how to make decisions themselves... thinking differently. If there is a situation which depends on me, of course, I'm always ready to help. But they must feel free in their subject to make decisions on any problems they have.

(Principal, S-D-I)

The principal added that 'there must be a clear process of who should do what... and the same stability, the same progress without me or without anyone from the staff'. There are examples of school principals supporting mid-level leaders (for example heads of methodological units) and teachers within their schools by 'assigning roles and not controlling every single detail', and also by introducing the rotation of staff every two years. In one of the schools we visited, the principal was trying to find ways to encourage teachers to take on leadership by 'giving some opportunities, some space to work, some responsibility' (Principal, S-E-V).

I always try to orient teachers, when criticising I suggest how to do something and that not everything depends on the authorities.

(Vice-Principal, S-B-VII)

Interestingly, in conversation with a few principals there were comments about the importance of intellectual freedom for teachers in order to foster their creativity. However, the challenge for some long-serving teachers with ingrained habits of acquiescence is how to use this suddenly given 'freedom'.

...today, a...teacher came and asked me: 'What should we do?' He is asking me to organise this again. I'm saying everything must be done without me ... There must be clear process of who should do what and I'm always saying this: the system must work. 
The same way, the same stability, the same progress, without me or without anyone from the staff.

(Principal, S-D-I)

At the same time, it was noted that there is a new young and enthusiastic generation in many schools across the country who are more likely to take initiatives.

\section{Creating new structures, roles and procedures}

We know that structures shape schools' capacities to develop learning communities. Reflection on and discussion of professional issues are key elements of the collaborative activity necessary to develop and connect professional learning communities (Stoll, 2011). However, the challenge for many practitioners in Kazakhstani schools is to find ways to deal with the perennial lack of time. Thus, in one school the SLT have to meet informally during 'breakfast time, lunch time to talk about what is going on, what kind of problems they have' $(\mathrm{S}-\mathrm{E}-\mathrm{V})$.

In another school there is a practice in place of asking teachers to complete a questionnaire at the end of the academic year in order to reflect on what contributed to positive results; to identify the problem areas in the school; and to evaluate the work of the administration over the year. Teachers are also asked to assess their own work during the year. The results of the questionnaire are analysed by the 'Working Groups' and reported back to the staff. This approach is aimed at developing teachers' reflective practice and supporting school improvement strategies:

...this way helps us observe the principle of collegiality and increase the participation rate. I believe that today objective reflection and self-evaluation is very important and teachers have to develop it.

(Vice Principal, S-B-VII)

There are some interesting examples of new roles in schools, which have been designed to produce a more collegial decision-making process. In some schools the advisory structure was called the 'Wise Group', in another the 'Champions'; while other schools have maintained a tight connection with the school's sponsors or an alumni foundation: 
...I have a Wise Group. I always listen to them. What we are doing in our management, in our education system - is it good? Where is there a problem? They have fifty years of experience. ...Some have witnessed at least $2,3,5$, reforms in education. They have seen different reforms. They see this very consciously ...

(Principal, S-D-I)

At the same time, as already indicated above, a few school leaders were working towards the development of what they called 'horizontal structures'. The idea behind this is to empower teachers who have completed $\mathrm{CoE}$ courses to be responsible for improving teaching. Despite some examples of teacher leadership, there was a shared view that more leadership development courses for both school principals and teachers are needed.

\section{Building a professional culture}

It was acknowledged that the school principal in practice 'cannot achieve everything on his/her own, there must be a community with a common ground, mutual understanding and interests'. Themes such as trust, respect, and the building of good relationships with others were identified by many participants. Creating a culture which is favourable to the children's learning and teachers' professional growth was seen by participants as one of the priorities of an effective school:

It is not about a programme or a sophisticated method - no. The main thing, in my opinion, is the school atmosphere ... In this respect, I believe that we create an amazing, unique atmosphere. ...The way students regard learning, the way teachers regard teaching - these things take years to build up....And it seems to me that it matters more than any methods or having several good teachers or several smart students.

(Principal, S-A-IV)

The challenge nearly all of the new schools face is culture building, as captured by the following comment:

...people here came from different schools, they have different teaching experience, and are from different age groups. People from the same school try to stick together. Such 
things are inevitable ...There is a variety of corporate parties that bring people together socially very well.

(Principal, S-A-VII)

Culture building takes time and, while people can agree with an overall idea, it is even more difficult to change their practices. One of the reasons is that teachers are prepared in the same way as they have been for many decades. Even if teachers realise the necessity of being open to changes, in practice it does not happen easily. In some schools, team teaching and joint planning were introduced with the aim of supporting the development of a collaborative culture.

[...] our department uses joint planning. We get together with all teachers who teach in the $11^{\text {th }}$ grades and we plan a lesson altogether... We develop activities and differentiation together, and distribute our responsibilities. A lesson plan we share with each other and thus we have the same materials for a lesson for every teacher

(Teacher, S-A-VI)

As indicated above, the context within which schools operate is characterised by the pressures of high-stakes accountability, increased workload and high expectations to perform which can lead to de-motivation. In this regard, some principals were trying to adopt various motivational strategies such as 'gratitude letters, letters for the award presentation from the city, days-off under an employment contract, making concessions, or giving small bonuses'. To some extent these strategies might be helpful. However, the key factor for teachers' motivation is a trusting environment in schools. The degree of paperwork reflected a lack of trust in teachers to do their job:

When we build trust in ...our school system, some documents won't need to be produced ... we ask for some documents because we cannot trust.

(Principal, S-D-I)

In short, the insights presented above highlight both opportunities and challenges for Kazakhstani schools in building capacity for implementing innovation. The opportunities for professional development are significant motivational factors for both teachers and school leaders. However, the question remains: how much do people change their practice behind the closed doors of their classrooms? The pressure to produce results does not allow enough time for critical reflection, constructive feedback and learning from mistakes. As a teacher 
claimed: '[we] do not have an opportunity to relax ... every day counts ... you must show results...we must always be first in competitions'.

\section{Discussion}

In this paper we have been concerned with examining how different schools in Kazakhstan create the conditions for capacity building in their day-to-day operations. We shall now discuss these issues and map the findings against a framework drawn from Hargreaves (2001) and Dimmock (2012) that guided our inquiry; and connect our broad findings to the literature. We shall then consider the implications of this for policy-makers and practitioners in Kazakhstan.

This study suggests that Kazakhstani school principals are working within an environment of strict bureaucratic regulations, a heavy burden of paper work and often being 'micro-managed' by local educational departments which control the school budget. The mindset with regard to management of nearly all the people in the schools we studied was one that assumed hierarchical decision making and control; the view was that schools must comply with the 'government educational standard' and the government decides everything that is planned in schools.

At the same time, the way school principals in Kazakhstan respond to the demands of educational reform depends on variations in the school context. The geographical context of Kazakhstan limits opportunities for teachers and principals in small remote schools to attend the latest professional development courses and seminars. Some respondents commented, for example: "we live on the periphery. It is difficult for us to get out there, we stew in our own juice here' (Principal, S-A-II). At the same time, respondents in other schools acknowledged that they have privileged conditions and claimed that the schools are cooperating with each other to share experience. There is no doubt that implementing educational innovation is much more challenging for schools on the periphery of the system than for big schools in large urban centres. It was often stated that the government has a responsibility to provide the necessary funding for schools to address issues of insufficient capacity. Of interest here is Stoll's (2009) argument that 'varied contexts and capacity necessitate differentiated capacity building' (p. 117). No two schools or districts are identical, and consequently a range of capacity building strategies needs to be adopted. This is especially obvious in the Kazakhstani context where there is a huge difference between a multigraded rural school and 
an urban mainstream school. In order to know what 'capacities' exist and what type of support will be most appropriate, it is important to understand the school context (Newmann et al. 2000). For example, in some schools it may be most productive to invest initially in the buildings and resources of the school (like small rural schools) - whereas in other schools the first order of priority would be the professional development of teachers' knowledge and skills in a particular instructional area. A more customised approach - or differentiated capacity building (Stoll, 2009, p.117) strategy - could result in differential emphases on different dimensions of capacity, depending on the local needs of the schools. Given this, it may be desirable for school principals to interpret and respond to new initiatives in different ways, suited to schools' own circumstances.

This study shows that a school culture plays an important role in the way school leaders create conditions for capacity building in their day-to-day operation. We learnt from our data that schools with a long history have developed tight teams of likeminded people and good trusting relationships and respect. However, in other schools there was evidence of a balkanised culture (Fullan and Hargreaves, 1992; Hargreaves, 1997) in which different groups are competing. Very often these schools had only been open one or two years and were clearly in the early stages of culture building. The role of school leaders in these circumstances is crucial. Some strategies were developed in Kazakhstani schools, such as: inviting professional psychologists who run training for teachers aimed at team building; seminars for teachers within the subject departments; and organising social events, of various kinds, like 'amateur' concerts. These approaches seem to be effective in supporting and developing trusting relationship.

A major finding of this study is the very positive reaction by teachers, principals and students to the Centres of Excellence professional development programme. However, the data usefully showed that some principals use professional development programmes to address capacity in their schools more comprehensively and successfully than others. The challenge for a majority of school leaders was how to turn the intellectual capital of trained teachers, their enriched knowledge about pedagogical ideas and practice and new skills in teaching methods, into organisational capital. In this respect the role of social capital collaboration, networks, trust and reciprocity is key. The data show that collaboration, group work, peer-to-peer learning, and networking supported the development of social capital within schools and between schools. Reciprocity in these relationships allowed all teachers regardless of their experience, age and their specialised subjects to learn, observe, and discuss ideas about pedagogy, curriculum and assessment. Furthermore, team work and learning 
about new teaching strategies, and observing them in practice, helped teachers feel valued and to appreciate their own learning and growth. Fullan $(2010 ; 2011)$ draws attention to the importance of creating 'cultures for learning', and argues that purposeful collaboration is one way of ensuring that there is coherence and centrality of purpose within any reform process. However, some teachers needed more time than others to develop the skills for effective collaboration. This is particularly important in Kazakhstan, where teachers' performance reflects their ranking, status and salary. In such a context, building collaborative working and thinking, along with respect and celebration of joint success, is not an easy endeavour. Not least the prescribed ministerial 'norms' and 'stavka' (i.e. the standard workload) along with a fear of being punished for mistakes could impact on teachers' motivation.

The question we posed earlier in this paper was: 'how much actual change in pedagogy has happened at the classroom level?' Our data provided insights that in some schools, when teachers use new approaches, students are more engaged and there is increased liking for the subject. For example, in one small rural school the 9 out of 11 final year students decided to take an examination in Biology because the teacher's lessons became very interesting and easy to understand. However, at the same time it needs to be recognised that:

$[\ldots]$ it is very difficult to change everything just in one year, not talking about three months or some shorter period... mostly teachers and students are still in the same mode of teaching and learning.

(Vice-Principal, Focus Group, S-E-V)

For some teachers, new practices, such as the development of critical thinking, represent a challenge because they continue to think in terms of 'right' and 'wrong' answers - a view which is reinforced by the mode of high stakes assessment in the Unified National Test. Innovation can also lead to teacher resistance. The challenge in 're-skilling' teachers in Kazakhstan is that while they may gain theoretical knowledge from professional courses, in practical terms they often struggle to apply this in their classes. The resistance of some teachers and the barriers to collegiality, collective responsibility and collaboration cannot be ignored (Barth 2006; Meier 2003).

Changing teachers' beliefs could be the most difficult task that school leaders as well as policy-makers need to deal with, our data suggests. Importantly, as we learn from this study, school leaders have to understand and see the values of new ideas and persuade the staff. In this situation some principals were trying to develop the various capacities and approaches that constituted the strengths of the school. A number of in-house activities such 
as half-day seminars and learning conversations were organised, which forced people to reexamine their practice and explore ways further to improve it. As results show, when some teachers changed their teaching approaches, that led to changes in beliefs about their overall practice, roles and their capacity. With the aim to model and disseminate effective practice the internal networks have been developed in some schools across Kazakhstan. These could be promising steps towards the development of professional learning communities. However, the sustainability of these networks was seen to be problematic because of time and space issues. Teachers are burdened with enormous amounts of paper work and it is not easy to find time to meet and critically discuss or engage with new practices.

This study reveals that in some schools a number of structural changes were implemented to enable the process of reform and support innovations. One important step was to create a strong team (e.g. Wise Groups; Champions). Nearly all of the school principals met regularly with their teams to discuss the latest ministerial decrees, new initiatives, pedagogical issues, various school matters, as well as teachers' and students' progress. The end result of these meetings was not only improved understanding of the situation in the school but also the opportunity to build a level of relational trust. As Tschannen-Moran and Hoy (2000, p.584) argue, 'trust makes a difference in student achievement, teachers' collective sense of efficacy, and overall school effectiveness'. In addition, in some schools there was a practice of staff rotation, which enabled teachers to take the opportunity to take on the role of head of methodological unit (e.g. subject department). While this can be seen as an opportunity for people to develop leadership practice and interaction skills, there was a view that not all teachers were ready to exercise leadership. This is to suggest that people need support to learn how to take a lead in initiatives. This can be achieved through 'a dialogic infrastructure' or 'set of structures and processes which provide [principals] with opportunities to engage in professional discourse [...] of sharing practice and discussing key issues in the practice of leadership' (Frost et al., 2014, p. 235). The evidence gathered from education reform around the world suggests that developing leadership capacity is essential. Dimmock and Goh (2011, p.231) argue that: 'leadership per se assumes a central role in the development of intellectual and social capital, and high leverage strategies'. Therefore, creating a 'culture for learning' (Fullan 2010) and the collaborative construction of meaning and knowledge are the key functions of leadership and, hence, of the main task in building organisational capacity. 


\section{Final thoughts}

One of the principals involved in this research remarked that 'we are living at a very interesting time - this is what I tell my teachers: we do not know exactly what tomorrow will bring, but we are sure it will be better. We are searching for our path' (Principal, S-A-IV). It is indeed a very significant but also challenging time for school leaders and teachers across Kazakhstan. The government's ambitious aim of transforming the entire system of education puts tremendous pressure on them all.

The evidence from large-scale reform efforts around the world does not provide any blueprint for success. But there is nevertheless a great deal to be learned from what may be seen as a 'shared' understanding across many writings about education reforms and social transformation that could aid the reform process in Kazakhstan. The international lessons suggest combinations of bottom-up and top-down forces as the most productive innovatory environment (Fullan, 2007). There is also a need for greater understanding of the role of local school conditions for reform. Clearly, shaping an evidence-based plan that meets the needs of a particular school's context remains a challenge (Hallinger and Heck 2011b; Day et al., 2010). If there is to be a real impact, systemic capacity building is required (Stoll, 2009; Fullan, 2009) and school principals must see this as their most important responsibility. Although there are fundamental principles and 'good' strategies, capacity building still requires a strong element of highly contextualised knowledge, which points to caution in 'translating' practice from one context to another (Silova 2005; Singh et al. 2013; SteinerKhamsi 2006).

The discussion above synthesises a number of factors which are important for capacity building from the perspective of the 'capital framework'. Our model differs somewhat from Dimmock (2012) as regards the role of context in creating conditions for capacity building strategies in a school. Figure 2 presents our proposed model of capacity building. 


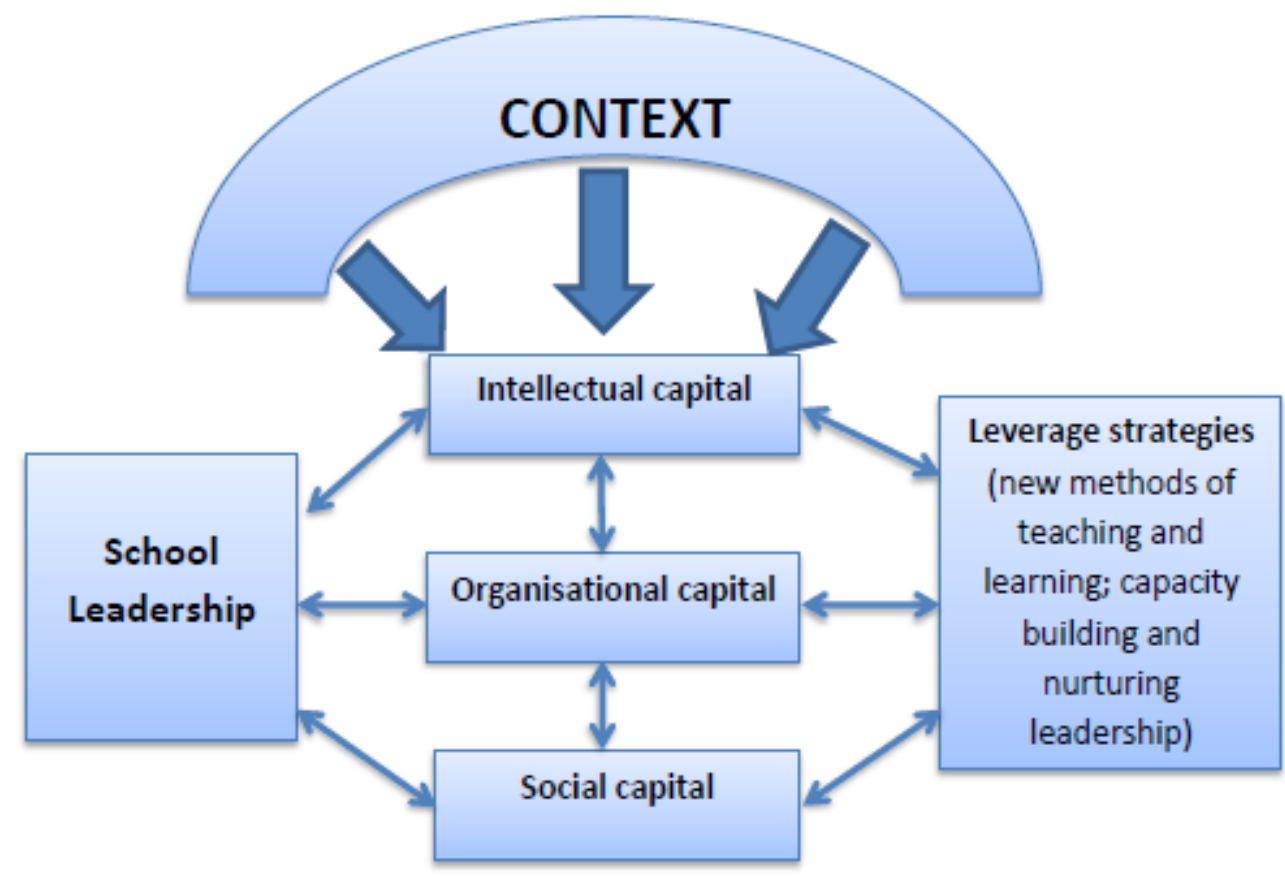

Figure 2. Conceptualisation of leadership as capacity building with context added. Source: Adapted from Dimmock (2012, p.191).

Intellectual capital can be enriched through re-skilling and re-culturing by promoting and supporting professional learning and creating a culture of learning at all levels: students; teachers; and the school as an organisation. However, intellectual capital is not as influential as social capital as a lead strategy. In order to enrich social capital it is necessary to create a supportive environment that involves trust and openness, participative decision making, team building, teacher collaboration and the celebration of success. This will lead to the creation of professional learning communities. To enact change more effectively, organisational capital needs to be used. Organisational capital falls within the capacity of leadership. As we argue throughout this article, a highly effective leverage strategy is to build capacity through collaboration and creating a culture for learning. Policy makers need to allow school leaders to change structures when and where necessary, to support teacher autonomy and to distribute leadership. Learning how to distribute leadership among teachers is a particular challenge, as well as understanding what leadership involves when it is distributed. Strategies may be required to involve teachers who are reluctant to take on leadership roles. It will not be possible to achieve a wider distribution of leadership without schools having greater autonomy to redesign themselves as organisations.

Our research suggests that capacity building strategies are necessary if innovations are to be implemented across all schools. Policy makers in Kazakhstan need to consider 
variations in the school context, to allow time for teachers to learn and adjust their skills, and reflect on their experience. And teachers also need ongoing support and mentoring. Significant changes in pre- and in-service teacher training programmes are needed. The evidence from international practice suggests that the development of teachers' research skills and capacity for self-reflection are key. Some promising steps have been undertaken by the Centre of Excellence professional development programme and it is also recognised that 'central to the success of the programme is the need to change [teachers'] beliefs as well as develop knowledge and skills' (Turner et al. 2014, p.103).

This article contributes to the existing literature about educational change in transitional societies and the role of leadership in this process. Since empirical studies on leadership and capacity building outside Anglophone countries are relatively few, our research extends the knowledge-base deriving from cross-cultural studies of educational leadership. The study presented here also adds to the scholarship that uses a capital framework to study organisational capacity building policy and practice. In the years to come, with the growing reciprocal interest between transitional and Western societies in large-scale educational reform, systemic capacity building and the effectiveness of leadership, there is a task for further research to document innovative and successful practice in this field, but always with sensitivity to the different cultures and contexts involved.

\section{Acknowledgements}

This article arises out of a partnership between the University of Cambridge Faculty of Education and the Graduate School of Education at Nazarbayev University. The research was supported in part by Nazarbayev University with funds from the Ministry of Education and Science the Republic of Kazakhstan. We are grateful to the research team, those who participated in this project and also to Dr Kairat Kurakbayev, who provided useful contribution and others colleagues who commented on earlier drafts of this paper.

\section{References}

Bain, A., Walker, A. and Chan, A. (2011). Self-organisation and capacity building: sustaining the change, Journal of Educational Administration, 49(6), 701-719.

Barth, R.S. (2006). Improving relations within the schoolhouse. Educational Leadership, 63, 9-13.

Becker, G. (1994). Human Capital: A Theoretical and Empirical Analysis with Special Reference to Education, Chicago, University of Chicago Press. 
Bourdieu, P. (1983). 'Forms of capital', in Richards, J.C. (ed) Handbook of Theory and Research for the Sociology of Education, New York, Greenwood Press, pp. 241-258.

Bridges, D., Kurakbayev, K. and Kambatyrova, A. (2014). 'Lost and found in translation? Interpreting the processes of international an international translation of educational policy and practice on Kazakhstan', in Bridges, D. (ed) Education Reform and Internationalisation: The case of school reform in Kazakhstan, Cambridge, Cambridge University Press, pp. 263-286.

Day, C., Sammons, P., Hopkins, D., Harris, A., Leithwood, K., Gu, Q., Brown, E. (2010). Ten Strong Claims About Successful School Leadership. Nottingham, UK: The National College for School Leadership.

Day, C. and Sammons, P. (2013). Successful Leadership: A Review of the International Literature, London, CfBT Education Trust.

Dinham, S. and Crowther, F. (2011). Sustainable school capacity building - one step back, two steps forward, Journal of Educational Administration, 49(6), 616-623.

Dimmock, C. (2012). Leadership, Capacity Building and School Improvement Concepts, Themes and Impact, London, Routledge.

Dimmock, C. and Goh, J.W.P. (2011). Transformative pedagogy, leadership and school organisation for the twenty-first century knowledge-based economy: The case of Singapore', School Leadership and Management, 31(3), 215-234.

Elmore, R.F. (2003). Knowing the Right Thing to Do: School improvement and performance-based accountability, Washington DC, NGA Center for Best Practices.

Frost, D., Fimyar, O., Yakavets, N. and Bilyalov, D. (2014). The role of the School Director in education reform', in Kazakhstan in Bridges, D. (ed) Educational Reform and Internationalisation: The Case of School Reform in Kazakhstan, Cambridge, Cambridge University Press, pp. 217-238.

Fullan, M. (1991). The New Meaning of Educational Change, 2nd edn, New York, Teachers College Press.

Fullan, M. (2003). The Moral Imperative of School Leadership, Thousand Oaks, CA, Corwin Press.

Fullan, M. (2005). Leadership and Sustainability: System Thinkers in Action, Thousands Oaks, CA, Corwin Press and Toronto, Ontario Principals' Council.

Fullan, M. (2007). The New Meaning of Educational Change, New York, Columbia University, Teachers College Press.

Fullan, M. (2010) Motion Leadership, Thousand Oaks, CA, Corwin Press.

Fullan, M. (2011). Choosing the wrong drivers for whole system reform, Centre for Strategic Education Seminar Series. East Melbourne, May 2011. Victoria, CSE/IARTV, seminar series paper no.204 [Online]. Available at http://edsource.org (Accessed 23 October 2014). 
Fullan, M. and Hargreaves, A. (1992). 'Teacher development and educational change', in Fullan, M. and Hargreaves, A. (eds) Teacher Development and Educational Change, (pp. 1-9), London, Falmer.

Gray, J., Hopkins, D., Reynolds, D., Wilcox, B., Farrell, S. and Jesson, D. (1999). Improving Schools: Performance and Potential, Buckingham, Open University Press.

Hallinger, P. and Heck, R.H. (1996). Reassessing the principal's role in school effectiveness: A review of empirical research, 1980-1995, Educational Administration Quarterly, 32(1), 5-44.

Hallinger, P. and Heck, R.H. (1998). Exploring the principal's contribution to school effectiveness: 1980-1995, School Effectiveness and School Improvement, 9(2), 157-191.

Hallinger, P. and Heck, R. (2010). Collaborative leadership and school improvement: Understanding the impact on school capacity and student learning, School Leadership and Management, 30(2), 95-110.

Hallinger, P. and Heck, R. (2011). 'Collaborative leadership and school improvement: Understanding the impact on school capacity and student learning', in Townsend, T. and McBeath, J. (eds) International Handbook of Leadership for Learning, (pp.469-486), Dordrecht, Springer.

Hargreaves, A. and Fullan, M. (2012). Professional Capital: Transforming Teaching in Every School, London, Routledge.

Hargreaves, D. (2001). A capital theory of school effectiveness and improvement', British Educational Research Journal, 27(4), 487-503.

Hargreaves, A. and Fink, D. (2006). Sustainable Leadership, San Francisco, Jossey-Bass.

Hargreaves, A. (1997). 'Introduction', in Hargreaves, A. (ed) Rethinking Educational Change with Heart and Mind: 1997 ASCD yearbook, Virginia, Association for Supervision and Curriculum Development, pp. 1-26.

Hopkins, D. and Jackson, D. (2001). Building the capacity for leading and learning', in Harris, A., Day, C., Hopkins, D., Hadfield, M., Hargreaves, A. and Chapman, C. (eds) Effective Leadership for School Improvement, (pp. 84-104), London, Routledge Falmer.

Hopkins, D. and Reynolds, D. (2001). The past, present and future of school improvement. towards the third age', British Educational Research Journal, 27(4), 457-459.

Hopkins, D., Harris, A. and Jackson, D. (1997). Understanding the school's capacity for development: Growth states and strategies, School Leadership and Management, 17(3), 401-411.

King, M.B. and Newman, F.M. (2001). Building school capacity through professional development: Conceptual and empirical considerations, International Journal of Educational Management, 15(2), 86-94.

Lambert, L. (1998). Building Leadership Capacity in Schools, Alexandria, VA, Association for Supervision and Curriculum Development. 
Leithwood, K. and Jantzi, D. (2006). Transformational school leadership for large-scale reform: Effects on students, teachers, and their classroom practices, School Effectiveness and School Improvement, 17(2), 202-227.

Leithwood, K., Seashore-Louis, K., Anderson, S. and Wahlstrom, K. (2004). How Leadership Influences Student Learning: A Review of Research for the Learning from Leadership Project, New York, Wallace Foundation.

Leithwood, K., Aitken, R., and Jantzi, D. (2001). Making schools smarter. Thousand Oaks, CA: Corwin Press.

Leithwood, K., Jantzi, D., and Steinbach, R. (1999). Changing leadership for changing times. Buckingham, UK: Open University Press.

Leithwood, K., and Louis, K.S. (Eds.). (1998). Organisational learning in schools. Lisse, The Netherlands: Swets and Zeitlinger.

Law on Education (2007). Act of the Republic of Kazakhstan no. 319-III, 27 July (amended and supplemented on 10 July 2012) [Online]. Available at www.online.zakon.kz (Accessed 23 October 2014).

McDonnell, L. and Elmore, R. (1987) 'Getting the job done: Alternative policy instruments', Educational Evaluation and Policy Analysis, 9, 133-178.

McLaughlin, M. (2008). Beyond "misery research" - new opportunities for implementation research, policy and practice, in Sugrue C. (ed) The Future of Educational Change: International perspectives, (pp.175-190), Abingdon, Oxford, Routledge.

Meier, D. (2003). In schools we trust: Creating communities of learning in an era of testing and standardization. Boston, MA: Beacon Press.

MoES (2012). Ministry of Education and Science, Republic of Kazakhstan, 'Rules for Competitive Substitution of Heads of State Institution of Secondary Education', No.57, 21 February 2012.

MoES (2009). Concerning Approval Standard Qualification Characteristics for Pedagogical Workers and Peer to Those. Order of the Minister of Education and Science of the Republic of Kazakhstan as pf 13 July 2009 of No.338. Available at http://www.edu.gov.kz/ru/postanovleniya-pravitelstva-respubliki-kazakhstan (Accessed 12 May 2015)

Mitchell, C. and Sackney, L. (2011). Profound Improvement: Building Capacity for a Learning Community, 2nd edn, London, Routledge.

Mulford, B. and Silins, H. (2009). Transformational leadership and organizational learning in schools, in Khine, M.S. and Saleh, I.M. (eds) Transformative Leadership and Educational Excellence: Learning organizations in the information age, (pp. 139-164), Rotterdam, Sense.

Newmann, F.M., King, M.B. and Youngs, P. (2000). Professional development that addresses school capacity: Lessons from urban elementary schools, American Journal of Education, 108(4), 259-299. 
OECD (2014). Reviews of National Policies for Education. Secondary Education in Kazakhstan, OECD Publishing [Online]. Available at http://dx.doi.org/10.1787/9789264205208-en (Accessed 23 October 2014).

OECD (2007). Getting It Right: Capacity building for local stakeholders in education, background paper for the OECD/Poland 'Effective Governance on the Local Level' conference, OECD Publishing [Online]. Available at http://www.oecd.org/edu/ceri/50294371.pdf (Accessed 23 October 2014).

Louis, K.S., Leithwood, K., Wahlstrom K.L. and Anderson, S.E. (2010). Learning from Leadership: Investigating the links to improved student learning, University of Minnesota and University of Toronto [Online]. Available at http://conservancy.umn.edu (Accessed 23 October 2014).

Senge, P. (1990). The Fifth Discipline: The Art and Practice of the Learning Organization, New York, Doubleday.

Silova, I. (2005). Travelling Policies: Hijacked in Central Asia. European Educational Research Journal, 4(1), 50-59.

Singh, P., Thomas, S. and Harris, J. (2013). Re-contextualising Policy Discourses: A Bernsteinian Perspective on Policy Interpretation, Translation, Enactment, Journal of Educational Policy, 28(4), 465-480.

Sleegers, P., and Leithwood, K. (2010) School development for teacher learning and change, In P. Peterson, E. Baker, and B. McGaw, (Eds.), International Encyclopedia of Education 7, (pp.557-562), Oxford, UK: Elsevier.

Steiner-Khamsi, G.(ed,) (2006). The Global Politics of Educational Borrowing and Lending, New York: Teachers College Press.

Standard Regulations for Operation of Educational Organisations of Primary, Basic Secondary and General Secondary Education Levels (2013). Decree of the Government of the Republic of Kazakhstan, No. 499, 20 May [Online]. Available at http://www.edu.gov.kz (Accessed on 20 August 2014).

State Program of Education Development in the Republic of Kazakhstan (2010). Decree of the President of the Republic of Kazakhstan no. 1118, 7 December [Online]. Available at http://www.edu.gov.kz (Accessed 20 August 2014).

Sterbinsky, A., Ross, S.M., and Redfield, D. (2006). Effects of comprehensive school reform on student achievement and school change: A longitudinal multi-state study. School Effectiveness and School Improvement, 17, 367-397.

Stoll, L. (2009). Capacity building for school improvement or creating capacity for learning? A changing landscape, Journal of Educational Change, 10(2), 115-127.

Stoll, L. and Earl, L. (2003). Making it last: Building capacity for sustainability, in Davies, B. and West-Burnham, J. (eds) Handbook of Educational Leadership and Management, (pp.491504), Harlow, Pearson Education. 
Stoll, L., Bolam, R., McMahon, A., Wallace, M. and Thomas, S. (2006). Professional learning communities: A review of the literature, Journal of Educational Change, 7(4), 221-258.

Spillane, J.P., Reiser, B.J. and Reimer, T. (2002). Policy implementation and cognition: Reframing and refocusing implementation, Review of Educational Research, 72(3), 387-431.

The World Bank (2014). SABER country report: Kazakhstan school autonomy and accountability 2013, World Bank [Online]. Available at http://saber.worldbank.org (Accessed on 9 August 2014).

Thoonen, E.E.J., Sleegers, P.J.C., Oort, F.J., Peetsma, T.T.D. (2012). Building school-wide capacity for improvement: the role of leadership, school organisational conditions, and teacher factors, School Effectiveness and School Improvement: An International Journal of Research, Policy and Practice, 23(4), 441-460.

Tschannen-Moran, M. (2014). Trust Matters: Leadership for Successful Schools, San-Francisco, CA, Jossey-Bass.

Tschannen-Moran, M. and Hoy, W.K. (2000). A multidisciplinary analysis of the nature, meaning, and measurement of trust, Review of Educational Research, 70(4), 547-593.

Turner, F., Wilson, E., Ispussinova, S., Kassymbekov, Y., Sharimova, A., Balgynbayeva, B. and Brownhill, S. (2014). Centres of Excellence: Systemwide transformation of teaching practice', in Bridges, D. (ed) Education Reform and Internationalisation: The Case of School Reform in Kazakhstan, (pp. 83-105), Cambridge, Cambridge University Press.

Yakavets, N. (2011). Leadership in extended schools: working in an inter-agency collaborative context', PhD thesis, The Open University, Milton Keynes.

Yakavets, N. (2014). Reforming society through education for gifted children: the case of Kazakhstan. Research Papers in Education, 29(5), 513-533.

\footnotetext{
${ }^{\mathrm{i}}$ Ministry of National Economy of the Republic of Kazakhstan Committee on Statistics. www.stat.gov.kz (accessed 9 August 2014)

ii Centres of Excellence $(\mathrm{CoE})$ is a large-scale professional development programme for schoolteachers in Kazakhstan which has been developed in cooperation between the University of Cambridge Faculty of Education, Cambridge International Examinations (CIE) and with Autonomous Educational Organisation Nazarbayev Intellectual Schools (AEO NIS). The primary aim of the CoE was to equip teachers to educate citizens of the $21^{\text {st }}$ century, i.e. to help pupils become independent self-motivated, engaged, confident, digitally competent, responsible and critically reflective learners, able to communicate in Kazakh, Russian and English (Turner et al., 2014, p.83). A cascade model of professional development was adopted for the CoE programme in order to reach as many teachers as possible (ibid., p.84). The content of the programme delivered through three levels. At the Level 3 the focus is on teachers change in the classroom; at the Level 2 - to support the professional development of other teachers-colleagues through coaching and mentoring; the Level 1 - is about bringing whole school change and 'leading learning in schools and networks'. As Bridges and Sagintaeva (2014, p. xxxiv) claim, 'it is these values and beliefs, embedded in a particular educational and professional culture, which the CoE programme sets out to change as a condition for changing more readily observable aspects of educational practice'.
} 